\title{
Avaliação preliminar in vivo do efeito hipocolesterolêmico do polvilho da fruta-de- lobo (Solanum lycocarpum A. St.-Hil.)
}

\author{
ROCHA, D.A. ${ }^{1}$; ABREU, C.M.P. ${ }^{1 *}$; SOUSA, R.V. ${ }^{2}$; CORRÊA, A.D. ${ }^{1}$; FONSECA, E.W.N. ${ }^{1}$ \\ ${ }^{1}$ Departamento de Química, ${ }^{2}$ Departamento de Medicina Veterinária, Universidade Federal de Lavras, Campus \\ Universitário, Caixa Postal 3037, CEP:37200-000, Lavras-Brasil “celeste@dqi.ufla.br
}

\begin{abstract}
RESUMO: O polvilho da fruta-de-lobo é um produto extraído da polpa da fruta-de-lobo verde (Solanum lycocarpum A. St.-Hil.), popularmente utilizado. Pouco se conhece a respeito desse polvilho, mas são atribuídos a ele vários efeitos terapêuticos, dentre eles a redução do colesterol. Este trabalho teve o objetivo de verificar a ação da administração do polvilho da fruta-de-lobo sobre animais hipercolesterolêmico. Utilizou-se 24 ratos Wistar fêmeas distribuídas em delineamento ao acaso, em três grupos contendo 8 animais em cada grupo. Estes grupos foram definidos como: controle normal $(\mathrm{CN})$, controle hipocolesterolêmico $(\mathrm{CH})$ e hipocolesterolêmico tratado $(\mathrm{HT})$. O grupo $\mathrm{CN}$ recebeu dieta comercial, os grupo $\mathrm{CH}$ e $\mathrm{HT}$ receberam a dieta comercial enriquecida de colesterol e ácido cólico e o grupo HT recebeu também, $100 \mathrm{mg}$ de polvilho da fruta-lobo, diariamente, por sonda orogástrica. O experimento teve uma duração de 6 semanas onde se avaliou o colesterol total sérico semanalmente, peso dos animais semanalmente e o consumo diário de ração. Ao término do experimento, foram avaliados os seguintes parâmetros: frações séricas de colesterol HDL, LDL+VLDL, peso do fígado, colesterol total hepático, lipídeos totais hepático e lâminas de microscopia foram feitas para avaliação dos hepatócitos. Não houve diferença significativa em relação ao peso corporal dos animais, ao consumo da dieta e nas análises de colesterol total sérico entre os grupos estudados. Avaliando-se a relação VLDL +LDL/ $\mathrm{HDL}$, os níveis encontrados no grupo HT foram significativamente menores que o grupo $\mathrm{CH}$. Já em relação ao colesterol hepático, o grupo HT mostrou níveis menores de colesterol que o $\mathrm{CH}$. Observou-se nos lipídeos hepáticos que não houve diferença significativa entre os grupo $\mathrm{CH}$ e HT, e no peso do fígado houve diferença significativa entre os grupos avaliados. Em relação à microscopia, os grupos hipercolesterolêmicos apresentaram discreta vacuolização no citoplasma dos hepatócitos. Concluiu-se, que o polvilho da fruta-de-lobo não influenciou o colesterol sérico dos animais, entretanto, reduziu os níveis de colesterol hepático.
\end{abstract}

Palavras-chave: fruta-de-lobo, polvilho, efeito hipocolesterolêmico

ABSTRACT: Preliminary evaluation of in vivo hypocholesterolemic effect of the flour of fruit-of-wolf (Solanum lycocarpum A. St.-Hil.). The fruit-of-wolf flour is a product extracted from the pulp of green fruit-of-wolf (Solanum lycocarpum A. St .- Hil.) and is commonly used. Little is known about this flour, but several therapeutic effects, including cholesterol reduction, are attributed to it. This study aimed to verify the action of the administration of fruit-of-wolf flour to hypercholesterolemic animals. We used 24 female Wistar rats allocated in randomized design to three groups containing 8 animals each. These groups were defined as normal control (CN), hypocholesterolemic control $(\mathrm{CH})$ and hypocholesterolemic treated rats $(\mathrm{HT})$. The $\mathrm{CN}$ group received a commercial diet, while the $\mathrm{CH}$ and the $\mathrm{HT}$ group received the commercial diet enriched with cholesterol and cholic acid; the HT group also received $100 \mathrm{mg}$ of fruit-of-wolf flour, daily, by orogastric tube. The experiment lasted for six weeks and the following characteristics were evaluated: weekly total serum cholesterol, weekly weight of animals and daily food intake. At the end of the experiment, we assessed the following parameters: serum cholesterol fractions HDL, LDL + VLDL, liver weight, liver total cholesterol, liver total lipids and microscopic slides were prepared for the evaluation of hepatocytes. There was no significant difference in body weight of animals, diet consumption and analysis of serum total cholesterol among the studied groups.

Recebido para publicação em 18/05/2011

Aceito para publicação em 25/01/2012

Rev. Bras. PI. Med., Botucatu, v.14, n.2, p.362-369, 2012. 
Assessing the relationship VLDL + LDL / HDL, the levels found for the HT group were significantly lower than those for the $\mathrm{CH}$ group. As regards liver cholesterol, the HT group showed lower cholesterol levels than the $\mathrm{CH}$ group. For liver lipids there was no significant difference between the $\mathrm{CH}$ and the $\mathrm{HT}$ group, and for liver weight there was no significant difference among the studied groups. As to microscopy, the hypercholesterolemic groups showed slight vacuolization in the cytoplasm of hepatocytes. It was concluded that fruit-of-wolf flour did not influence the serum cholesterol of animals but reduced the levels of liver cholesterol.

Key words: fruit-of-wolf, flour, hypercholesterolemic effect

\section{INTRODUÇÃO}

A fruta-de-lobo é vegetal da família Solanaceae que pode ser encontrada em todo o território brasileiro, principalmente nas regiões de cerrado (Santos \& Coelho, 2002). A partir do fruto verde é obtido um polvilho, que é utilizado popularmente na redução de colesterol. De acordo com estudos realizados por Kusano et al. (1987), os alcalóides das solanáceas, solamargina, solanina e solasodina, também encontrados em S. lycocarpum, são capazes de inibir a conversão enzimática de diidrolanosterol em colesterol, agindo num ponto além daquele em que age a enzima HMG-CoA redutase, no metabolismo deste lipídeo.

A hipercolesterolemia é uma condição que se caracteriza pela presença de taxas elevadas de colesterol no sangue, o que afeta um quinto da população brasileira, especialmente pessoas com mais de 45 anos, segundo a Sociedade Brasileira de Cardiologia. Embora tenha funções orgânicas essenciais, como a produção de hormônios e de sais biliares, o colesterol representa um dos fatores de risco mais importantes para o desenvolvimento de doenças cardiovasculares, quando em excesso.

O colesterol é um composto alicíclico com um núcleo ciclopentano- peridrofenantreno hidroxilado no C3, uma ligação dupla no C5 e uma cadeia alifática ramificada com 8 carbonos em C17. Essa molécula é formada de 27 átomos de carbono e constitui o maior esterol dos tecidos animais (Janeiro et al., 2006; Nelson \& Cox, 2010).

A síntese do colesterol é um processo complexo e energeticamente custoso. Sendo assim, o organismo deve regular esta síntese (Rang et al., 2007; Hardman et al., 2007). A produção desregulada de colesterol pode levar a doenças graves. Quando a soma do colesterol endógeno (sintetizado) e o exógeno (dieta) excede a quantidade necessária para satisfazer à síntese de membranas, sais biliares e esteróides, pode ocorrer acúmulo de colesterol nas paredes de vasos sanguíneos (placas de ateroma), resultando em obstrução desses vasos (aterosclerose) e podendo causar sérios problemas cardíacos (Mahan \& Scott-Stumpp, 2002).

Pacientes hipercolesterolêmicos devem ser tratados para reduzir os riscos de ataques cardíacos.
Se, no organismo humano, $70 \%$ do colesterol são provenientes da síntese endógena e 30\% da alimentação, os pacientes devem associar ao tratamento uma dieta com baixos níveis de colesterol (Brody, 1998).

O colesterol é lipídeo essencial ao organismo humano, mas, em altas quantidades, torna-se prejudicial à saúde. Com isso, o presente estudo foi realizado com o objetivo de avaliar o possível efeito hipocolesterolêmico atribuído ao polvilho da frutade-lobo.

\section{MATERIAL E MÉTODO}

O experimento foi realizado no campus da Universidade Federal de Lavras (UFLA), em Lavras, MG. Os frutos da espécie vegetal Solanum lycocarpum A.St.-Hil. utilizados neste estudo foram coletados na área de pastagem do Departamento de Zootecnia da Universidade Federal de Lavras, a exsicata está depositada no herbário Esal 00836.

\section{Obtenção do polvilho}

Oitenta frutas-de-lobo foram coletadas no mês de abril entre os horários 13:00-14:00h. Destas, foram selecionadas 61, pesando, em média, $350 \mathrm{~g}$ cada e levando-se em consideração o grau de maturação, excluindo-se as frutas maduras e as muito verdes.

Os frutos foram pesados, lavados com água e, em seguida, descascados e partidas em bacia contendo água destilada. As sementes foram retiradas e a polpa picada em pedaços pequenos e pesadas. A polpa foi colocada em um liquidificador industrial e batida com água destilada na proporção de 2:1 (polpa/ água destilada) por 2 minutos. A polpa homogeinizada foi filtrada em um tecido de algodão e prensada, para garantir que toda a amostra passasse pelo filtro. $O$ filtrado foi colocado em béquer e levado a refrigerador $\left(4^{\circ}-8^{\circ} \mathrm{C}\right)$, por 6 horas, para decantar.

Após decantação, o sobrenadante foi desprezado e o precipitado foi lavado com água destilada e colocado novamente para decantar no refrigerador por 12 horas. No dia seguinte, a amostra foi lavada e decantada novamente. O sobrenadante 
foi desprezado e observou-se a formação de uma fração clara no fundo do béquer e outra escura acima desta, que foi desprezada. A fração clara foi colocada em uma bandeja e levada à estufa ventilada, a $30^{\circ} \mathrm{C}$, por três dias. A fração clara seca foi denominada de polvilho. Este foi triturado, pesado e, em seguida, armazenado em recipiente de vidro hermeticamente fechado e protegido da luz, sob temperatura ambiente, para análises posteriores.

\section{Animais}

Foram utilizadas 24 ratas adultas jovens (Rattus novergicus), da linhagem Wistar, provenientes do Biotério do Departamento de Medicina Veterinária da Universidade Federal de Lavras, com peso médio inicial de 196,9 $\pm 13,4 \mathrm{~g}$. Os animais foram divididos aleatoriamente em três grupos, sendo controle normal $(\mathrm{CN})$, controle hipercolesterolêmico $(\mathrm{CH})$ e hipercolesterolêmico tratado (HT), com oito animais em cada grupo. $\mathrm{O}$ grupo $\mathrm{CN}$ recebeu dieta comercial, o grupo $\mathrm{CH}$ recebeu dieta comercial enriquecida com colesterol e ácido cólico e o grupo HT também recebeu dieta comercial enriquecida com colesterol e ácido cólico, além do polvilho da fruta-de-lobo. No grupo tratado com o polvilho da fruta-de-lobo, os animais receberam $100 \mathrm{mg} \mathrm{dia}^{-1}$ desse fitoterápico em apenas uma dose. Foi utilizada sonda orogástrica para a aplicação e o polvilho da fruta-de-lobo foi dissolvido em $1 \mathrm{~mL}$ de água filtrada. Os animais foram tratados durante 42 dias.

Esses animais foram mantidos em gaiolas individuais, em ambiente com temperatura controlada de $22^{\circ} \mathrm{C}$ a $23^{\circ} \mathrm{C}$ (ciclo claro: escuro de 12 horas), com acesso à ração para roedores e água ad libitum.

Este trabalho foi apreciado e aprovado pelo Comissão de Ética no Uso de Animais da Universidade Federal de Lavras-UFLA (Parecer № 006/ 2009).

\section{Preparo da dieta hipercolesterolêmica}

A hipercolesterolemia foi induzida com ração suplementada, preparada a partir da ração comercial e enriquecida com colesterol e ácido cólico. A ração comercial utilizada para ratos foi triturada em um liquidificar industrial até uma granulometria pequena. Em seguida, acrescentaram-se, a cada $100 \mathrm{~g}$ de ração, $0,50 \mathrm{~g}$ de colesterol e $0,25 \mathrm{~g}$ de ácido cólico e a ração foi umedecida com água, modelada e levada a uma estufa ventilada, a $35^{\circ} \mathrm{C}$, por dois dias, tempo suficiente para que a ração secasse.

Diariamente, foram colocados 25 gramas dessa ração para os animais dos grupos hipercolesterolêmicos tratado e controle. Os animais do grupo controle normal receberam a mesma dieta comercial, porém, sem adição de colesterol e ácido cólico.

\section{Peso dos animais e consumo de ração}

Os animais foram alojados em gaiolas metabólicas individuais, alimentados com $25 \mathrm{~g}$ das rações por dia, pesados semanalmente, em balança digital Bel Engineering ${ }^{\circledR}$ e 0 consumo de ração anotado diariamente, sendo calculado sobre as sobras verificadas no dia seguinte.

\section{Determinação do colesterol sérico total}

As amostras de sangue foram coletadas da cauda dos animais no período vespertino (14-15 horas), sem jejum. Na determinação do colesterol total do soro sanguíneo dos animais, foi utilizado o kit enzimático-colorimétrico, marca Analisa ${ }^{\circledR}$.

Os ésteres de colesterol foram hidrolisados pelo colesterol esterase, formando o colesterol livre que, após a oxidação pela enzima colesterol oxidase, formou o peróxido de hidrogênio. Este, reagindo com fenol e 4-aminoantipirina, por meio de reação oxidativa catalisada pela peroxidase, produziu uma quinonimina de cor vermelha. A absorbância do complexo formado foi diretamente proporcional à concentração do colesterol da amostra.

A leitura de absorbância foi realizada em um espectrofotômetro 700S Femto, em comprimento de onda de $500 \mathrm{~nm}$.

Determinação do colesterol na fração HDL

A determinação do colesterol-HDL no soro dos animais foi realizada utilizando-se o kit enzimático-colorimétrico, marca Analisa ${ }^{\circledR}$.

Nesse método, os quilomícrons e as lipoproteínas de baixa e de muito baixa densidade são quantitativamente precipitadas com fosfotungstato e íons de magnésio e centrifugadas, a 4.000 rpm, por 10 minutos. Esse precipitado foi desprezado. O colesterol ligado às lipoproteínas de alta densidade (HDL) foi determinado no sobrenadante, utilizandose a mesma metodologia de dosagem do colesterol total.

A leitura de absorbância foi realizada em um epectrofotômetro 700S Femto, em comprimento de onda de $500 \mathrm{~nm}$. +VLDL

Determinação do colesterol na fração LDL

O colesterol total é a soma das frações de colesterol (HDL, LDL e VLDL). Dessa forma, pode-se calcular o valor de LDL + VLDL, que é igual ao colesterol total final - HDL.

\section{fígado}

Análises bioquímicas e histológicas no

O fígado dos animais foi retirado, imediatamente pesado e uma parte colocada em solução de formalina para serem fixados para as análises histológicas. A outra parte foi congelada, 
liofilizada por dois dias até peso constante, triturada, e armazenada em um dessecador para posteriores análises de colesterol e lipídeos hepáticos.

\section{Determinação de colesterol total hepático}

Foi utilizado o método de extração proposto por Folch et al. (1957). Foram colocados em tubo de ensaio, $100 \mathrm{mg}$ de fígado com $1.900 \mu \mathrm{L}$ de solução de clorofórmio-metanol 2:1, triturados com o auxílio de bastão de vidro e agitados em seguida em vórtex, por 1 minuto. Ao material triturado foram adicionados $400 \mu \mathrm{L}$ de metanol. Esse material foi então centrifugado a $3.000 \mathrm{rpm}$ durante dez minutos. $\mathrm{O}$ sobrenadante foi transferido para outro tubo de ensaio e adicionados $800 \mu \mathrm{L}$ de clorofórmio e $640 \mu \mathrm{L}$ de solução de $\mathrm{NaCl}$ a $0,73 \%$. Depois desse procedimento, houve nova centrifugação a 3.000 rpm durante dez minutos, o sobrenadante foi descartado e o precipitado foi lavado três vezes com solução de Folch (3\% de clorofórmio, $48 \%$ de metanol, $47 \%$ de água e $2 \%$ de $\mathrm{NaCl}$ a 0,2\%). Os extratos lipídicos foram secos em estufa ventilada, a $37^{\circ} \mathrm{C}$, ressuspenso com $1 \mathrm{~mL}$ de álcool isopropílico para posterior determinação de colesterol utilizando o kit enzimático, marca Analisa ${ }^{\circledR}$.

\section{Determinação dos lipídeos hepáticos totais}

Para determinar a porcentagem de lipídeos totais foi utilizada a metodologia proposta pela AOAC (1990). O fígado triturado foi desengordurado em cartucho de celulose (cerca de 2 gramas da amostra) durante oito horas em aparelho de Soxhlet, utilizandose éter etílico como solvente. Os cálculos foram feitos com base na matéria seca.

\section{Eutanásia dos animais}

Ao término do experimento, os animais foram anestesiados e realizou-se uma laparotomia mediana no sentido pélvico-cranial das cavidades abdominais e torácica para coletar amostras de sangue pela técnica de punção cardíaca (exsanguinação). Em seguida, coletou-se o fígado de cada animal.

\section{Análise histopatológica}

Após a fixação do fígado em formalina, os órgãos foram seccionados transversalmente, desidratados e diafanizados em temperatura ambiente. Em seguida, foram incluídos em parafina e feitos corte de microtomia com espessura de 5 mícrons e corados com hematoxilina-eosina (HE). Por meio dessa técnica, podem-se diferenciar porções basófilas e acidófilas do tecido estudado. A hematoxilina é acidófila, ou seja, tem afinidade por substâncias ácidas podendo corar os núcleos. A eosina é basófila, tendo afinidade pelo citoplasma, fibras colágenas e outras substâncias básicas das células (Atlas Eletrônico de Histologia, 2009).

\section{Análise estatística}

Os dados foram analisados utilizando-se o programa Sanest. Para a análise de variância foi utilizado o delineamento inteiramente casualizado (DIC) no esquema fatorial $3 \times 7$ (grupos $\times$ semanas), com 8 repetições para os parâmetros: peso dos animais, consumo de ração e colesterol sérico total. Para as análises de HDL e as realizadas no fígado, o delineamento foi o DIC com três tratamentos e oito repetições.

\section{RESULTADO E DISCUSSÃO}

\section{Peso dos animais e consumo de ração}

Os resultados dos pesos dos animais encontram-se na Tabela 1. Nota-se que não houve diferença significativa entre o peso dos animais no tempo zero do experimento comparado com o peso da última semana.

Os animais ganharam peso na mesma proporção não sendo influenciado pela dieta com colesterol e ácido cólico (grupos $\mathrm{CH}$ e HT) e pelo polvilho da fruta-de-lobo (grupo HT).

Tem sido evidenciado o papel de dietas hipercolesterolêmicas em aumentar o tecido adiposo estocado em animais experimentais (Bernardes et al., 2004). Ribeiro et al. (2008) analisaram o ganho de peso de ratos que receberam uma dieta rica em colesterol e ratos que receberam dieta balanceada, em machos e em fêmeas. Observouse que o ganho de peso foi proporcional em todos os grupos estudados.

Em relação ao consumo de ração (Tabela 2), não houve diferença significativa entre os grupos avaliados, mostrando que os animais consumiram as rações na mesma quantidade. Isso indica que colesterol e ácido cólico, adicionados à ração comercial, não influenciaram no consumo da mesma. O ganho de peso (Tabela 1) foi proporcional ao consumo da dieta. Assim, não houve diferença entre os grupos estudados em relação a esses parâmetros.

TABELA 1. Peso inicial e final de ratos Wistar, nos três tratamentos estudados por 42 dias. Grupos CN (controle normal), $\mathrm{CH}$ (Controle hipercolesterolêmico) e HT (hipercolesterolêmico tratado).

\begin{tabular}{ccc}
\hline Grupos & Peso inicial $(\mathbf{g})$ & Peso Final $(\mathbf{g})$ \\
\hline CN & 190,05 & 213,39 \\
CH & 210,27 & 232,15 \\
HT & 201,59 & 221,17 \\
\hline
\end{tabular}

Pesos médios no início e no final do experimento em gramas dos três grupos (médias não diferem entre si, pelo teste de Tukey, $\mathrm{pd} \leq 0,05)$. 
TABELA2. Consumo médio de ração por dia ( $\mathrm{g}$ dia $\left.{ }^{1}\right)$ de ratos Wistar nos três tratamentos estudados por 42 dias. Grupos CN (controle normal), $\mathrm{CH}$ (controle hipercolesterolêmico) e HT (hipercolesterolêmico tratado).

\begin{tabular}{cc}
\hline Grupos & Consumo de ração $\left(\mathbf{g ~ d i a}^{-1}\right)$ \\
\hline $\mathrm{CN}$ & 17,72 \\
$\mathrm{CH}$ & 19,23 \\
$\mathrm{HT}$ & 18,02 \\
\hline
\end{tabular}

Teores médios de consumo de ração em gramas dos três grupos (médias não diferem entre si, pelo teste de Tukey, $p d \leq 0,05$ ).

\section{Colesterol sérico total}

Observa-se, pelos dados da Tabela 3, que os animais do grupo controle apresentaram níveis séricos de colesterol total de $42,57 \mathrm{mg} \mathrm{dL}^{-1}$. Os animais que receberam colesterol e ácido cólico, adicionados à ração tiveram aumento em torno de $100 \%$ nos níveis séricos de colesterol total, indicando hipercolesterolemia.

Em vários estudos com interesse em avaliar o efeito hipocolesterolêmico utilizam-se ratos como modelo experimental, por ser fácil o manuseio, pela possibilidade de trabalhar com vários grupos simultaneamente, por não ocupar grandes espaços físicos, e redução de gastos. Entretanto, os ratos são resistentes para desenvolver hipercolesterolêmia e aterosclesrose, possivelmente devido ao aumento da conversão do colesterol em ácidos biliares no fígado (Duarte, 1996).
Pelos dados da Tabela 3, verifica-se que não houve diferença significativa entre as médias dos animais dos grupos $\mathrm{CH}$ e HT. Durante as semanas do ensaio os valores dos animais dos grupos hipercolesterolêmicos foram próximos, indicando que o polvilho da fruta-de-lobo não apresentou nenhum efeito hipocolesterolêmico. O experimento teve duração de 42 dias, tempo suficiente para reduzir o colesterol dos animais. De acordo com estudos de Silva et al. (2004) com a berinjela, também da família Solanaceae, não foi observado nenhum efeito hipocolesterolêmicos em pacientes hiperlipidêmicos.

O grupo controle normal apresentou média de $42,57 \mathrm{mg} \mathrm{dL}^{-1}$ de colesterol total, valor próximo ao encontrado por Piedade \& Canniatti-Brazaca (2003), de $53 \mathrm{mg} \mathrm{dL}^{-1}$ no tempo zero de tratamento. No presente trabalho, observou-se na primeira semana que os grupos $\mathrm{CN}, \mathrm{CH}$ e HT apresentaram valores próximos para os níveis séricos de colesterol total.

\section{Colesterol nas frações HDL, LDL+VLDL e LDL+VLDL/HDL}

A concentração de colesterol é importante, porém, as de colesterol HDL devem ser consideradas, já que o HDL é um transportador do colesterol. Ele carrega o colesterol das células do corpo para o fígado, para reutilizá-lo, convertê-lo em ácidos biliares ou descartá-lo, devendo ser elevado em indivíduos saudáveis.

Os valores médios de HDL, LDL+VLDL e LDL+VLDL/HDL nos soros dos animais encontram-se na Tabela 4.

TABELA 3. Níveis séricos de colesterol total em $\mathrm{mg} \mathrm{dL}^{-1}$ de ratas Wistar, nos três tratamentos estudados por 6 semanas. Grupos CN (controle normal), $\mathrm{CH}$ (controle hipercolesterolêmico) e HT (hipercolesterolêmico tratado).

\begin{tabular}{ccccccccc}
\hline Tratamentos/Semanas & $\mathbf{0}$ & $\mathbf{1}$ & $\mathbf{2}$ & $\mathbf{3}$ & $\mathbf{4}$ & $\mathbf{5}$ & $\mathbf{6}$ & Média \\
\hline $\mathrm{CN}$ & 50,32 & 38,87 & 24,94 & 40,43 & 58,93 & 36,73 & 47,78 & $42,57 \mathrm{~B}$ \\
$\mathrm{CH}$ & 48,88 & 85,68 & 89,91 & 109,42 & 125,93 & 118,62 & 137,00 & $103,33 \mathrm{~A}$ \\
$\mathrm{HT}$ & 49,87 & 90,75 & 93,86 & 112,49 & 133,78 & 117,44 & 124,75 & $102,15 \mathrm{~A}$ \\
\hline
\end{tabular}

Níveis séricos médios de colesterol total em $\mathrm{mg} \mathrm{dL}^{-1}$ dos três grupos (médias seguidas pelas mesmas letras nas colunas não diferem entre si, pelo teste de Tukey, $\mathrm{pd} \leq 0,05)$.

TABELA 4. Valores médios de HDL-colesterol $\left(\mathrm{mg} \mathrm{dL}^{-1}\right)$, VLDL + LDL $\left(\mathrm{mg} \mathrm{dL}^{-1}\right), \mathrm{e} \mathrm{VLDL}+\mathrm{LDL} / \mathrm{HDL}\left(\mathrm{mg} \mathrm{dL}^{-1}\right)$, do soro de ratos nos três tratamentos, estudados por 42 dias. Grupos CN (controle normal), $\mathrm{CH}$ (controle hipercolesterolêmico) e HT (hipercolesterolêmico tratado)

\begin{tabular}{cccc}
\hline Grupos & $\begin{array}{c}\text { HDL colesterol } \\
\left(\mathbf{m g ~ d L}^{-1}\right)\end{array}$ & $\begin{array}{c}\text { VLDL }+\mathrm{LDL} \\
\left(\mathbf{m g ~ d L}^{-1}\right)\end{array}$ & $\begin{array}{c}\text { VLDL +LDL/HDL } \\
\left(\mathbf{m g ~ d L}^{-1}\right)\end{array}$ \\
\hline $\mathbf{C N}$ & $33,60 \mathrm{~B}$ & $13,01 \mathrm{C}$ & $0,39 \mathrm{~B}$ \\
$\mathbf{C H}$ & $69,67 \mathrm{~A}$ & $64,46 \mathrm{~A}$ & $0,92 \mathrm{~A}$ \\
$\mathbf{H T}$ & $74,65 \mathrm{~A}$ & $47,75 \mathrm{~B}$ & $0,65 \mathrm{AB}$ \\
\hline
\end{tabular}

Valores médios de HDL colesterol em mg dL ${ }^{-1}, \mathrm{VLDL}+\mathrm{LDL}$ em mg dL${ }^{-1}$ e VLDL+LDL/HDL em mg dL ${ }^{-1}$ dos três grupos (médias seguidas pelas mesmas letras nas colunas não diferem entre si, pelo teste de Tukey, $\mathrm{pd} \leq 0,05$ ). 
No grupo controle normal, a média do nível sérico de HDL colesterol foi de $33,60 \mathrm{mg} \mathrm{dL}^{-1}$, valor próximo ao encontrado por Piedade \& CanniattiBrazaca (2003), que foi de $34 \mathrm{mg} \mathrm{dL}^{-1}$. Esse valor médio é encontrado em ratos adultos sadios alimentados com dieta comercial balanceada para ratos.

Nos ratos dos grupos $\mathrm{CH}$ e $\mathrm{HT}$, os valores médios encontrados foram de 69,97 $\mathrm{mg} \mathrm{dL}^{-1}$ e 75,65 $\mathrm{mg} \mathrm{dL}^{-1}$, respectivamente. Houve diferença significativa entre os grupos controle e hipercolesterolêmicos. Essa grande diferença no teor de HDL colesterol encontrado nos animais desses dois grupos pode ser atribuída ao aumento do colesterol total nesses animais, ou seja, maior oferta de substrato necessário para sintetizar novas lipoproteínas de HDL.

Oliveira et al. (2002) encontraram valores próximos de colesterol HDL nos grupos hipercolesterolêmicos ao avaliarem flavonóides em ratos hiperlipidêmicos.

Henriques et al. (2008) também encontraram valores próximos ao encontrado neste trabalho, 62 $\mathrm{mg} \mathrm{dL}^{-1}$ ao avaliar a influência dietética de ração à base de mix de fibras sobre a glicemia e o perfil metabólico de lipídeos em ratos Wistar.

Em relação ao HDL colesterol, apesar do aumento observado nos grupos $\mathrm{CH}$ e $\mathrm{HT}$, a relação HDL colesterol/colesterol total apresentou valores bem próximos aos do grupo controle normal. Os valores encontrados para $\mathrm{CN}, \mathrm{CH}$ e $\mathrm{HT}$ foram, respectivamente, 0,79, 0,67 e 0,73. Sabe-se que quanto menor é esta relação, maior é o risco de que ocorram doenças cardiovasculares, pois a fração HDL colesterol está relacionada com a inibição da deposição das LDL nas paredes arteriais e com 0 transporte reverso de colesterol (Duarte, 1996).

Os valores da fração de colesterol LDL+VLDL encontram-se na Tabela 4, indicando que no grupo tratado com polvilho da fruta-de-lobo houve redução do LDL + VLDL quando comparado ao grupo não tratado. Avaliando-se a relação VLDL +LDL/HDL na Tabela 4 observa-se que os níveis encontrados no grupo HT foram significativamente menores que o grupo $\mathrm{CH}$, mostrando a influência do polvilho nessas lipoproteínas plasmáticas. Quanto menor essa relação, menores os riscos de doenças cardiovasculares.

\section{Análises do fígado}

Os resultados das análises realizadas no fígado, tais como peso do fígado, colesterol total e lipídeos totais, encontram-se na Tabela 5.

Nos grupos $\mathrm{CH}$ e HT (Tabela 5) o peso do fígado foi maior, entretanto, esses animais apresentaram maior peso corporal e consumiram uma dieta rica em colesterol e ácido cólico. Por isso, provavelmente, o fígado estava com maior peso. Já o grupo controle normal apresentou menor peso corporal e consumiu dietas sem colesterol e ácido cólico, por isso, a massa do fígado foi menor.

No trabalho realizado por Lima (2008), os ratos que apresentaram menor peso hepático foram aqueles que consumiram dietas isentas de colesterol e ácido cólico. Dietas com maiores teores lipídios podem induzir a maior lipidemia (esteatose), com provável sobrecarga hepática e, consequentemente, uma hipertrofia celular decorrente de maior solicitação fisiológica (Bookman, 2006). Esse fato pode ser comprovado pelo excesso de lipídeos totais, verificado na Tabela 5.

O peso do fígado pode ser influenciado em casos de dietas com fibras, que podem reduzir a massa desse órgão. Por isso, provavelmente, os animais do grupo tratado $(\mathrm{HT})$ apresentaram menor peso do fígado do que os animais do grupo $\mathrm{CH}$ já que o polvilho tem fibras. Gallaher (2000) verificou que ratos alimentados com dieta contendo $10 \%$ de glucomanana, citosana e glucomana + citosana diminuíram o peso do fígado em relação ao grupo controle, com $10 \%$ de celulose.

Cherem \& Bramosrki (2008), ao avaliarem o efeito da quitosana em ratos hiperlipidêmicos, não observaram redução no peso do fígado nos ratos que receberam as fibras. Kaminski et al. (2008), ao analisarem diferentes formulações de multimisturas sobre a resposta biológica em ratos, avaliaram a massa do fígado dos animais e também não observaram diferença significativa entre os grupos estudados.

Ao avaliar o PF/PC, observa-se que não houve diferença significativa entre os grupos hipercolesterolêmicos, provavelmente devido à dieta enriquecida com colesterol e ácido cólico desses animais. Já o grupo controle apresentou valor menor devido a não ingestão de colesterol e ácido cólico.

Os valores médios observados neste trabalho para o colesterol total do fígado dos ratos e apresentados na Tabela 5 variam de 8,41 a $39,82 \mathrm{mg}$ $\mathrm{g}^{-1}$, demonstrando que houve um aumento de $473 \%$ entre o grupo $\mathrm{CN}$ e o $\mathrm{CH}$ e de $283 \%$ entre os grupos $\mathrm{CN}$ e HT. Nos grupos que receberam dieta com colesterol e ácido cólico o colesterol total foi maior, mas, entre o grupo tratado com o polvilho da frutade-lobo e o não tratado, o teor de colesterol hepático foi maior no grupo CH. Lima (2008), ao avaliar dietas com diferentes teores de fibras e $1 \%$ de colesterol nas dietas de ratas, encontrou teor de colesterol hepático variando de 16,09 a $39,31 \mathrm{mg} \mathrm{g}^{-1}$, um aumento de 244\%. Já Anderson et al. (1994) verificaram aumento de mais de $300 \%$ de colesterol hepático ao incluírem $1 \%$ de colesterol e 0,2 de colato de sódio.

No presente experimento, o colesterol total hepático dos animais tratados com polvilho da fruta- 


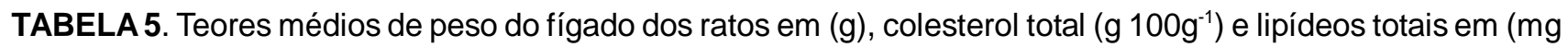
$\mathrm{g}^{-1}$ ), obtidos ao final dos 42 dias de experimento.

\begin{tabular}{ccccc}
\hline Grupos & Peso $(\mathbf{g})$ & PF/PC $(\%)$ & $\begin{array}{c}\text { Colesterol } \\
\mathbf{m g ~ g}^{-1} \text { de fígado }\end{array}$ & $\begin{array}{c}\text { Lipídeo } \\
\mathbf{( g ~ 1 0 0 g}^{-1} \mathbf{)}\end{array}$ \\
\hline $\mathrm{CN}$ & $7,69 \mathrm{C}$ & $3,45 \mathrm{~B}$ & $8,41 \mathrm{C}$ & $6,94 \mathrm{~B}$ \\
$\mathrm{CH}$ & $9,52 \mathrm{~A}$ & $4,10 \mathrm{~A}$ & $39,82 \mathrm{~A}$ & $18,05 \mathrm{~A}$ \\
$\mathrm{HT}$ & $8,74 \mathrm{~B}$ & $3,93 \mathrm{~A}$ & $23,84 \mathrm{~B}$ & $15,80 \mathrm{~A}$ \\
\hline
\end{tabular}

Teores médios de peso do fígado dos ratos, em g, PF/PC em \%, colesterol total, em $\mathrm{mg} \mathrm{g}^{-1}$, lipídeos totais $\mathrm{g} 100 \mathrm{~g}^{-1}$ dos três grupos (médias seguidas pelas mesmas letras nas colunas não diferem entre si, pelo teste de Tukey, $\mathrm{pd} \leq 0,05)$.

de-lobo apresentou redução de 40,13\%, quando comparado ao grupo $\mathrm{CH}$, indicando que o polvilho pode ter contribuído para essa redução.

Os valores médios observados neste trabalho para os lipídeos totais do fígado de ratos, apresentados na Tabela 5, variaram de $6,94{\mathrm{~g} 100 \mathrm{~g}^{-1}}^{-1}$

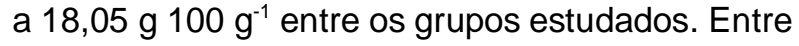
os grupos hipercolesterolêmicos não houve diferença signiticativa; entretanto, os lipídeos totais hepáticos dos ratos tratados com polvilho da fruta-de-lobo apresentaram redução de $12,46 \%$ em relação aos lipídeos hepáticos dos animais do grupo $\mathrm{CH}$.

Segundo Beher (1962) e Portman (1960), o ácido cólico, além de potencializar o efeito do colesterol dietético aumentando a absorção, pode, por outro lado, inibir a conversão de colesterol a ácidos biliares favorecendo o acúmulo de lipídios no fígado e promovendo o chamado "fígado gorduroso" nos animais.

Lima (2008), ao analisar a farinha da casca do maracujá no controle da lipidemia em ratas também observou maiores níveis de lipídeos totais no fígado dos animais que receberam, na dieta, colesterol e colato de sódio.
As dietas hipercolesterolêmicas foram capazes de induzir maior quantidade de lipídeos hepáticos nos tratamentos que consumiram colesterol e ácido cólico.

\section{Análise histopatológica}

Foi realizada análise histológica do fígado dos animais utilizados no experimento. O fígado foi coletado e pesado antes dos cortes necessários para a realização das lâminas.

Foram feitas oito lâminas do fígado de cada grupo estudado nesse experimento e, em seguida, realizou-se a observação por microscopia ótica.

Os cortes histológicos do fígado dos animais estão representados nas Figuras 1A, 1B e 1C.

Observa-se, nos cortes histológicos (Figuras 1A, 1B e 1C), que o grupo hipercolesterolêmico apresentou discreta vacuolização no citoplasma dos hepatócitos, quando comparado ao grupo controle.

A vacuolização ou degeneração dos hepatócitos (esteatose hepática) ocorre todas as vezes que um agente interfere no metabolismo dos ácidos graxos da célula, aumentando a síntese ou dificultando a utilização, transporte ou excreção

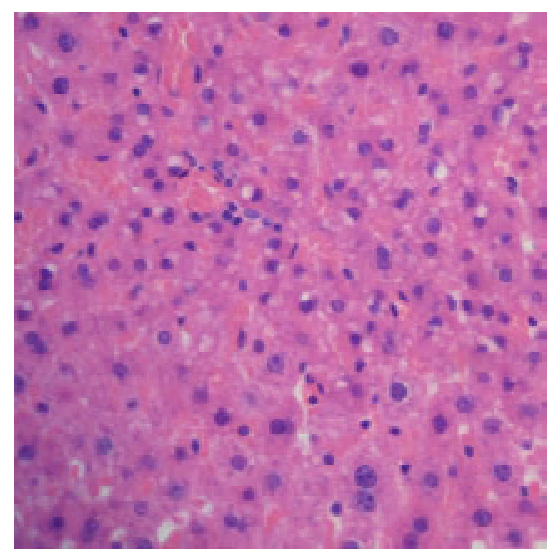

FIGURA 1A. Corte histológico de fígado corado com HE, obtido de ratos do grupo controle. Aumento de $40 X$.

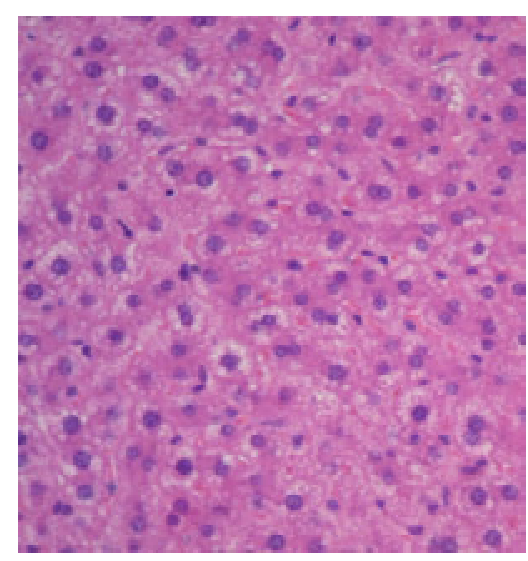

FIGURA 1B. Corte histológico de fígado corado com HE, obtido de ratos do grupo controle hipercolesterolêmico do grupo controle. Aumento de $40 \mathrm{X}$.

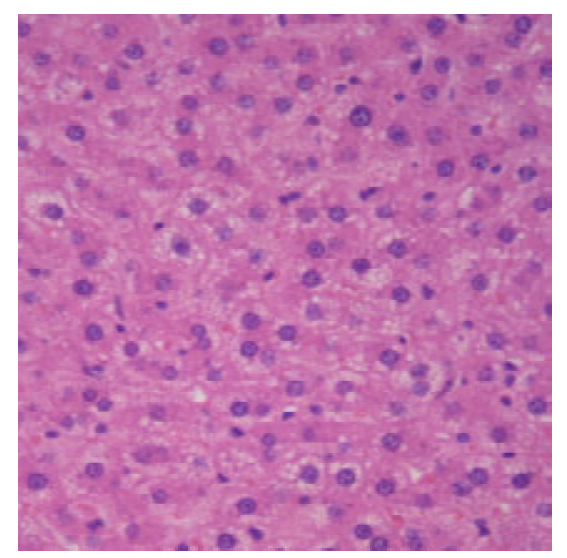

FIGURA 1C. Corte histológico de fígado corado com HE, obtido de ratos do grupo hipercolesterolêmico tratado. Aumento de $40 \mathrm{X}$. 
(Brasileiro Filho, 2004). A vacuolização discreta observada no citoplasma dos grupos hipercolesterolêmicos (Figuras 1B e 1C) deve-se, provavelmente, à dieta com colesterol e ácido cólico que esses animais receberam, durante os 42 dias de experimento.

\section{CONCLUSÃO}

O polvilho da fruta-de-lobo utilizado neste estudo não foi eficaz na redução dos níveis séricos de colesterol total, na concentração, via, e forma, utilizadas; entretanto, mostrou efeito redutor nos níveis de colesterol hepático.

\section{AGRADECIMENTO}

Ao Conselho Nacional de Desenvolvimento Científico e Tecnológico (CNPq), pelo apoio financeiro.

\section{REFERÊNCIA}

ANDERSON, J.M.; JONES, A.E.; RIDDEL-MASON, S. Ten different dietary fibers have significantly different effects on serum and liver lipids of cholesterol-fed rats. The Journal of Nutrition, v.124, n.1, p.78-83, 1994.

ASSOCIATION OF OFFICIAL AND AGRICULTURAL CHEMISTRY. Official Methods of Analysis. 5.ed. Washington: AOAC, 1990. 1200p.

ATLAS ELETRÔNICO DE HISTOLOGIA. Preparação de lâminas histológicas. Disponível em: <http://www. danielbranco.com.br/atlasi/txt_prep.html> Acesso em: 20 jan. 2009.

BRASILEIRO FILHO, G. Bogliolo patologia geral. 3.ed. Rio de Janeiro: Guanabara Koogan, 2004. 367p.

BEHER, W.T.; BAKER, G.D.; PENNEY, D.G. A comparative study of the effects of bile acids and cholesterol on cholesterol metabolism in the mouse, rat, hamster and guinea pig. The Journal of Nutrition, v.79, n.63, p.52330, 1962.

BERNARDES, D. et al. Efeitos da dieta hiperlipídica e do treinamento de natação sobre o metabolismo de recuperação ao exercício em ratos. Revista Brasileira de Educação Física e Esporte, v.18, n.2, p.191-200, 2004. BOOKMAN, I.D. et al. Distinguishing nonalcoholic steatohepatitis from fatty liver: serum-free fatty acids, insulin resistance, and serum lipoproteins. Liver International, v.26, n.5, p.561-71, 2006.

BRODY, T. Nutrition biochemistry. 2.ed. San Diego: Academic Press, 1998, 1006p.

CHEREM, A.R.; BRAMOSRKI, A. Excreção de gordura fecal de ratos (Rattus norvegicus, Wistar), submetidos a dietas hiperlipídicas e hipercolesterolêmicas suplementadas com quitosana. Revista Brasileira de Ciências Farmacêuticas, v.44, n.4, p.701-6, 2008.

DUARTE, H.S. Elaboração e formulação de um alimento formulado em pó, rico em fibra, no controle da hipercolesterolemia.Viçosa: UFV, 1996. 137p.
FOLCH, J.; LESS, M.; SLOANE-STANLEY, G.H.A. Simple method for isolation and purications of total lipids from animal tissue. Journal og Biological Chemistr, v.226, n.1, p.407-11, 1957.

GALLAHER, C.M.; MUNION, J. H.; WISE, J. Cholesterol reduction by glucomanana e chitosan is mediated by changes in cholesterol absorption and acid bile and fat excretion in rats. Minnesota: American Society for Nutrition Science, 2000.

HARDMAN, J.G.; MOLINOFF, P. B.; GILMAN, A.G. As bases famacológicas da terapêutica. 11.ed. Rio de Janeiro: McGraw Hill, 2007. 1848p.

HENRIQUES, G.S. et al. Avaliação da influência dietética de uma ração enriquecida em mix de fibras sobre a glicemia e o perfil metabólico de lipídios em ratos wistar. Revista do Médico Residente, v.10, n.2, p.58-66, 2008. JANEIRO, A. et al. Monografia do colesterol. Lisboa: Faculdade de Ciências da Universidade de Lisboa, 2006. $28 p$.

KAMINSKII, T.A. et al. Moural, G.B. Diferentes formulações de multimisturas sobre a resposta biológica em ratos. Revista Ciência Rural, v.38, n.8, p.2327-33, 2008.

KUSANO, G. et al. Solanum alkaloids as inhibitors of enzmatic conversionof dihydrolanosterol into colesterol. Chemical \& Pharmaceutical Bulletin, v.35, n.12, p.43213, 1987.

LIMA, H.M. Farinha da casca do maracujá associada ao exercício físico no controle da lipidemia em ratas. 2008. 87p. Tese (Doutorado em Ciência dos alimentos) Universidade Federal de Lavras, Lavras.

MAHAN, L.K.; SCOTT-STUMPP, K. Alimentos e nutrição: dietoterapia. 10.ed. São Paulo: Roca, 2002.1157p.

NELSON, D.L.; COX, M.M. Lehninger princípios de bioquímica. 5.ed. São Paulo: Sarvier, 2010. 1304p.

OLIVEIRA, T.T. et al. Efeito de diferentes doses de flavonóides em ratos hiperlipidêmicos. Revista de Nutrição, v.15, n.1, p.45-51, 2002.

PIEDADE, J.; CANNIATTI-BRAZACA, S.G. Comparação entre o efeito do resíduo doabacaxizeiro (caules e folhas) e da pectina cítrica de alta metoxilação no nível de colesterol sangüíneo em ratos. Ciência e Tecnologia em Alimentos, v.23, n.2, p.149-56, 2003.

PORTMAN, O.W.; BRUNO, D. Various natural and modified bile acids in cholesterol metabolism. Journal of Nutrition, v.73, n.61, p.329-36,1960.

RANG, H.P.; DALE, M.M.; RITTER, J.M. Farmacologia. 6.ed São Paulo: Guanabara Koogan, 2007. 848p.

RIBEIRO, A.M. et al. Efeitos de uma dieta hipercolesterolêmica sobre o peso corporal e metabolismo lipídico de ratos Jovens. In: CONGRESSO BRASILEIRO DE MEDICINA VETERINÁRIA, 35., 2008, Gramado. Anais... Gramado: Sociedade Brasileira de Medicina Veterinária, 2008.

SANTOS, M.O.; COELHO, A.D.F. Variabilidade Genética entre populações de lobeira (Solanum lycocarpum St. Hill.). 2002. 162p. Dissertação (Mestrado em Biologia) Universidade Federal de Juiz de Fora, Juiz de Fora.

SILVA, G.E.S. et al. Ausência de efeito hipolipemiante da Solanum melongena L. (Berinjela) em pacientes hiperlipidêmicos. Arquivos Brasileiros de Endocrinologia \& Metabologia, v.48, n.3, p.368-73, 2004. 